\title{
Assessment of Changes in Cardiovascular Parameters among Petrol Pump Attendants in Ughelli, Delta State Nigeria
}

\section{OVUAKPORAYE, SI}

Department of Human Physiology, Faculty of Basic Medical Sciences, College of Health Sciences, Delta State University, Abraka. Nigeria *Email: simonovuakpo2006@yahoo.com

\begin{abstract}
Petrol pump attendants are group of workers that are daily exposed to petrol fumes across petrol filling stations in major cities within Nigeria and sub-Sahara Africa. The objective of this study is to evaluate the effect of petrol fumes on changes in some cardiovascular parameters among petrol pump attendants in Ughelli, Delta State Nigeria by measuring arterial blood pressure and calculating pulse and mean arterial pressure of 150 petrol attendants with age, sex matched control within Ughelli metropolis and its environs. Data obtained show that the arterial blood pressure, pulse and mean arterial pressure ranged from 108/60 - 140/92, 48 - 80 and $76-126 \mathrm{mmHg}$ respectively. The result also revealed that mean arterial pressure significantly $(\mathrm{p}<0.05)$ increase in the petrol pump attendant. More so, the systolic and diastolic blood pressure increased in a duration of exposure dependent manner with significance $(p<0.05)$ in petrol pump attendants working for more than five years. The mean arterial pressure was significantly $(\mathrm{p}<0.05)$ increased in subjects working as petrol pump attendants for less than five years and five years or more. Data also showed that the pulse pressure was not adversely affected in the petrol pump attendants. In conclusion, this study has established that there are changes in cardiovascular parameters of petrol pump attendants as shown with an increase in systolic, diastolic and mean arterial pressure.
\end{abstract}

\section{DOI: DOI: $\underline{\text { https://dx.doi.org/10.4314/jasem.v23i11.26 }}$}

Copyright: Copyright (C) 2019 Ovukporaye. This is an open access article distributed under the Creative Commons Attribution License (CCL), which permits unrestricted use, distribution, and reproduction in any medium, provided the original work is properly cited.

Dates: Received: 07 October 2019; Revised: 11 November 2019; 24 November 2019

Keywords: Assessment, Cardiovascular Parameters, Petrol pump attendants

In the recent past there has been an increased concern about exposure to potentially harmful substances in both workplaces and elsewhere in the environment (Bourke, 2003). This study was carried out among filling station attendants in Ughelli Delta State, Nigeria. Exposure to petrol fumes was evaluated in terms of work place exposure of more than a year, the number of vehicles filled per day and work hour per week. Ughelli metropolis is located along the EastWest federal highway for commuters travelling from the south-west to south-eastern part of Nigeria. Petrol also known as Premium motor spirit $\{\mathrm{PMS}\}$ or gasoline is a complex combination of hydrocarbons and non-hydrocarbons. About $95 \%$ of the components in petrol vapour or fumes are alicyclic compounds and less than 2\% aromatics. (Gupta and Dogra, 2002). Urbanization has resulted in great increase in number of automobiles, petrol filling stations and workshops for fixing vehicles. Workers engaged in these environment are continuously exposed to petrol and diesel fumes (Uzma et al., 2008). Petrol pump workers are vulnerable to petroleum hydrocarbons through intake of contaminated food, water, dermal exposure or inhalation of vapour and air-borne soil (Azeez et al., 2012). At these petrol pumps, as there is no provision of self service, the fuel filling attendants are employed for fuelling of vehicles (Kesavachandran et al., 2006). Apart from filling tasks, these fuel dispensers are also engaged in works like unloading of fuel and daily checking of fuel levels in the storage tanks (Periago and Prado, 2005). Additionally, these fuel attendants are exposed to the emissions liberated from the tailpipes of the vehicles as many motorists routinely do not turn down their vehicles while getting refuelled thus, making these attendants substantially exposed to various gasoline derivatives (Aleemuddin et al., 2015). Information on changes in cardiovascular parameters due to exposure to petroleum by fuel pump attendants are inadequate. Hence there is the need for a study of this nature. The current study is aimed at assessing the changes in cardiovascular parameters of petrol pump attendants induced by fumes from petrol and to ascertain the effect of duration of exposure on arterial blood pressure pulse pressure and mean arterial pressure among fuel attendants.

\section{MATERIALS AND METHODS}

Study Design: The material used during the study were sphygmomanometer, stethoscope and questionnaire. It is a cross sectional study which adopted one on one interview and observation methods. Questions were asked and answers recorded regarding education and

*Email: simonovuakpo2006@yahoo.com 
socioeconomic status, work experience and use of protective equipment like face masks.

Sample Size/Sampling Techniques: The sampling technique used was stratified random sampling method being that the population is made up of both gender with different age range.

Subject Selection: Subjects were selected till the number of the required age range was measured and recorded. The study group included the petrol pump attendants working at least $8 \mathrm{~h} /$ day or at least $40 \mathrm{hr}$ per week for more than 1 year at various petrol pumps in Ughelli metropolis.

Only consenting subjects who satisfy the inclusion criteria were selected. The controls were recruited to match for age, sex, and were drawn from different residents in various supermarkets and the two urban markets in Ughelli metropolis.

Inclusion Criteria: Petrol station attendant between the ages of 18-40years. Duration of employment of more than 1year. Petrol station workers who dispenses PMS for more than 8 hours a day or for at least 40 hours per week, in line with criteria set by American Conference of Governmental and industrial hygienist and National Institute of occupational safety and health(NIDSH) of America, on occupational exposure limit to gasoline or Premium Motor Spirit.

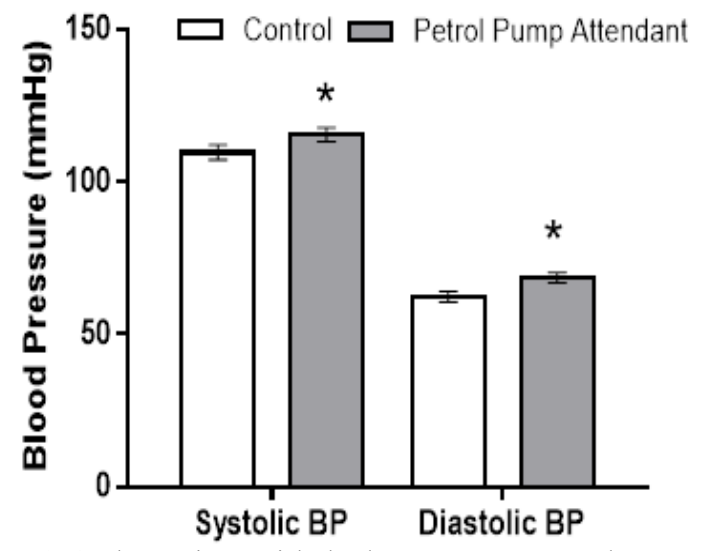

Fig 1. Changes in Arterial Blood Pressure among Petrol Pump Attendants in Ughelli

*: $\mathrm{p}<0.05$ when compared to control

Exclusion Criteria: Petrol pumps attendants who do not give consent, smokers. Co-morbid clinical condition that may affect or compromise the cardiovascular system of subjects or participants, for example congenital or acquired chest or spine deformity like kyphosis, scoliosis or pigeon chest or recent trauma or operation of chest. Malignancy, Left Ventricular failure, Hypertension, past history of occupational exposure to substances that have been documented to affect cardiovascular function.

Data Collection: This involved two steps. (1). Collection of relevant data using an intervieweradministered questionnaire (2). Measuring and recording the blood pressure of subjects at work place with permission from their immediate supervisor. Blood pressure measurement was then carried out on subjects that gave informed consent using sphygmomanometer and stethoscope

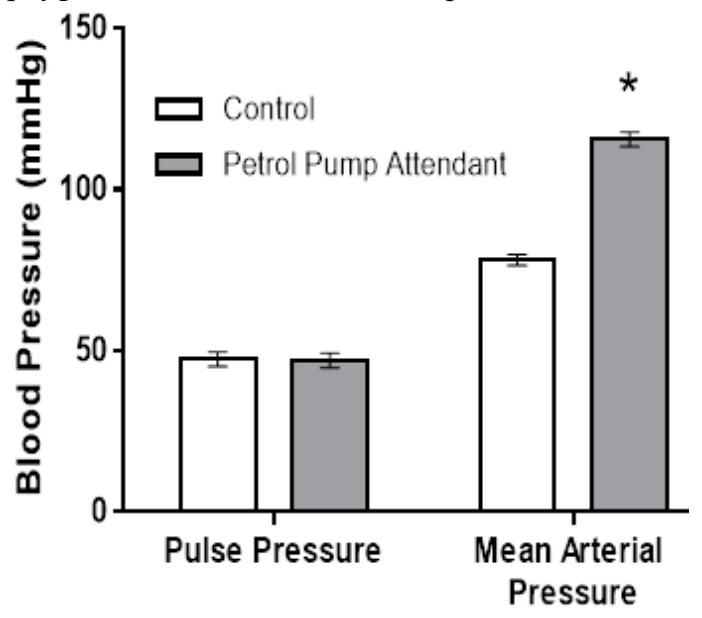

Fig 2. Changes in Pulse Pressure and Mean Arterial Pressure of Petrol Pump Attendants in Ughelli

*: $\mathrm{p}<0.05$ when compared to control

Ethical Clearance: Ethical clearance was sought and obtained from the ethical committee of the Faculty of Basic Medical Sciences, Delta State University, Abraka, Consent forms were carefully designed to seek approval of each participant prior to the study (REC/FBMS/DELSU/19/66).

Data Analysis: Data were represented as mean standard deviation. Statistical Analysis was done using the IBM SPSS version 21.0 software, while means were compared using One-Way Analysis of Variance (ANOVA) and Student's t-Test. Significance was accepted at p-level less than 0.05 .

\section{RESULTS AND DISCUSSION}

This result show representation of cardiovascular parameters among petrol pump attendants in Ughelli, Delta State. The present study determined the changes and duration of exposure on systolic, diastolic, pulse and mean arterial pressure in fuel attendants.

Changes in Arterial Blood Pressure of Petrol Pump Attendants in Ughelli: The study showed that systolic and diastolic blood pressure of petrol pump attendants significantly $(\mathrm{p}<0.05)$ increased when compared to control. 
Changes in Pulse Pressure and Mean Arterial Pressure among Petrol Pump Attendants in Ughelli: The pulse pressure of participants were observed to be within normal range when compared to that of control. However, there was significant $(p<0.05)$ increase in the mean arterial pressure of petrol pump attendants when compared to control.

Effect of Duration of Exposure to Fuel Particles on Arterial Blood Pressure among Petrol Pump Attendant in Ughelli: It was observed that both systolic and diastolic blood pressure of the attendants increased in a duration of exposure dependent manner. There was no statistical significance difference when the systolic and diastolic blood pressures of petrol pump attendants exposed to fuel particles for less than five years was compared to control. Conversely, exposure to fuel particles for five years or more caused a significant $(\mathrm{p}<0.05)$ increase in the systolic and diastolic blood pressures of petrol pump attendants when compared to control.

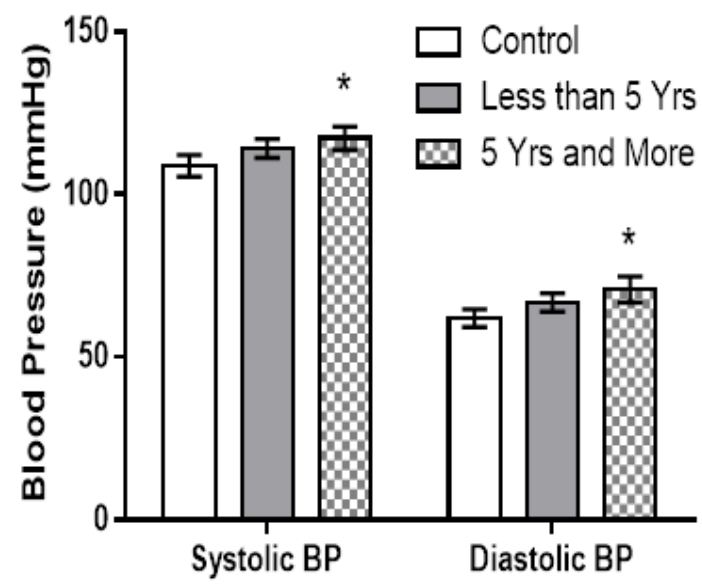

Fig 3 Effect of Duration of Exposure to Fuel Particles on Arterial Blood Pressure of Petrol Pump Attendant in Ughelli; *: $\mathrm{p}<0.05$ when compared to control

Effect of Duration of Exposure to Fuel Particles on Pulse Pressure and Mean Arterial Pressure of Petrol Pump Attendant in Ughelli: The study showed that duration of exposure to fuel particles by petrol pump attendants did not affect pulse pressure. It was also observed that the pulse rate of petrol pump attendants exposed to fuel particles of less than five years and five years or more remained within control range, and there was no statistical significance difference. Furthermore, significant $(p<0.05)$ increase in mean arterial pressure was recorded in petrol pump attendants exposed to fuel particles for less than five years and five years or more but this increase in not dependent on duration of exposure.

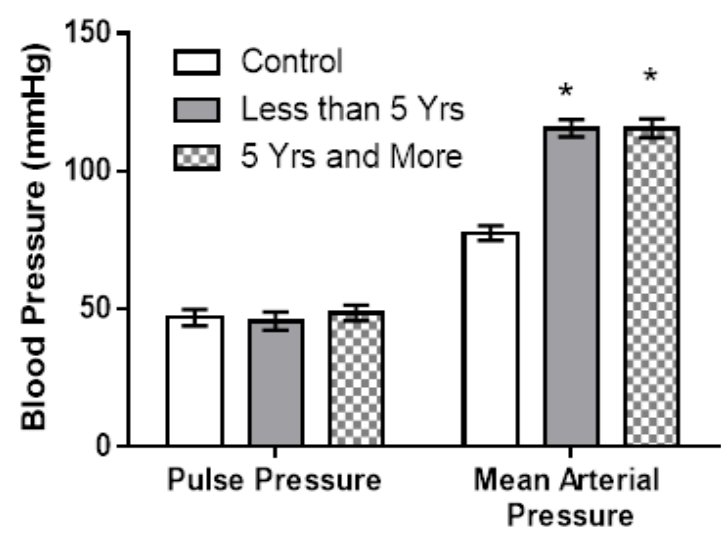

Fig 4. Effect of Duration of Exposure to Fuel Particles on Pulse Pressure and Mean Arterial Pressure of Petrol Pump Attendant in Ughelli. *: $\mathrm{p}<0.05$ when compared to control

Petroleum products are volatile, hence are readily inhaled. Petrol pump attendants in Ughelli Metropolis, rarely checked their health status nor wore personal protective equipment to minimize the adverse health effects of petroleum products vapours, therefore warranting this study. This study showed that inhalation of petroleum fumes led to significant $(p<0.05)$ increase in systolic, diastolic and mean arterial pressure, while the pulse pressure was not adversely affected. Furthermore, the mean value of systolic as well as diastolic blood pressure increases with increased years of exposure; this change was found to be statistically significant $(\mathrm{p}<0.05)$ at the highest duration of exposure to petroleum particles (five or more years). The mean arterial pressure was also increased in the petrol pump attendant, though not in a duration of exposure dependent manner but significance $(<0.05)$ was recorded when compared to control. Conversely, the mean value of pulse pressure was not increased according to year of exposure, this change was not found to be statistically significant. Findings of this research agrees with outcome of previous study done by Azeez et al. (2015). Also Akintonwa et al. (2003) showed that there was significant elevation in both systolic and diastolic blood pressure, about $12.5 \%$ of the petrol attendants had systolic blood pressure varying from 141-160mmHg while $28.6 \%$ had diastolic blood pressure ranging from $91-110 \mathrm{mmHg}$. Data from this study also corroborates previous study (Azeez et al., 2012) that documented the pressor effect of petroleum hydrocarbon. Levecchio and Fulton, (2001) earlier attributed the ability of petroleum hydrocarbon to enhance the sensitization of myocardium to catecholamines, impaired vagal activity and increased Baroreceptor activity with resultant vasoconstriction and increased arterial blood pressure. 
Previous study from Mills (2005) showed that inhaling of petroleum hydrocarbons is responsible for the rise in arterial and mean arterial pressure, this substantiate the findings of this study. The study further reported that inhalation of hydrocarbons elicited vasoconstriction and impaired vascular tone. The pressor effect caused by petrol fumes or particles could be attributed to the ability of hydrocarbons to cause sensitization of myocardium to catecholamines, possible hindrance of vasovagal event as explained by Levy and Pappano, (2001) with consequent sympathetic effect as well as elevation of arterial blood pressure as observed in the cardiovascular parameters with exception to pulse pressure, in the petrol attendants. Bartoli et al. (2009) revealed that inhalation of petroleum hydrocarbons leads to increase baroreflex sensitivity. Baroreceptors are sensors in the blood vessels which function in the short term as a part of the baroreflex negative feedback system. (Levecchio and Fulton, 2001). These mechanoreceptors reset in the maintenance of a normal arterial pressure (Ganong, 1997). Therefore, the pressor effects of the petrol fumes or particles observed in petrol attendants could explain the increase in arterial blood pressure and mean arterial pressure. It is important to know that petroleum products are risk factors of cardiovascular dysfunctions (Anderson and Loomis, 2003; El-Menyar et al., 2005) which are major problems among refinery workers, inhalant abusers, as well as the general population at large since they form an important component of life, thus accounting for clinical complications resulting in increased mortality (Ritchie et al., 2003). The severity of cardiovascular complications linked with petroleum products inhalation could be related to the various components petroleum products. The volatile aromatic hydrocarbons contents in petrol may be responsible for the pressor effect and rapid adjustment of the baroreflex to the elevated arterial blood pressure compared to the increased baroreflex sensitivity found in diesel and kerosene-exposed rats, with lower aromatic hydrocarbons.

Conclusion: In conclusion, this study has established that there are changes in cardiovascular parameters of petrol pump attendants induced by the inhalation of petrol fumes as shown with an increase in systolic, diastolic and mean arterial pressure. The current study has also demonstrated the variability of cardiovascular function seen in petroleum pump attendants.

Acknowledgement: The author wishes the appreciate Miss Deborah Ofudje, my research assistance for her assistance in data collection in the course of this study. However, this research was self-funded.

\section{REFERNCES}

Bourke SJ. (2003). Lecture notes on Respiratory medicine. 6th edition. Blackwell (publisher): Berlin; 145- 155

Uzma N; Salar BM; Kumar BS; Aziz N; David MA; Reddy VD. (2008). Impact of organic solvents and environmental pollutants on the physiological function in petrol filling workers Int J Environ Res Public Health. 5(3):139-46.

Azeez OM; Anigbogu CN; Akhigbe RE. (2015). Cardiotoxicity induced by inhalation of petroleum products. J. Afr. Ass. Physiol. Sci. 3 (1): 14-17.

Kesavachandran C; Rastogi SK; Anand M; Mathur N; Dhawan A. (2006). Lung function abnormalities among petrol-pump workers of Lucknow, North India. Curr Sci.; 90(9):1177-8.

Periago JF and Prado C. (2005). Evolution of occupational exposure to environmental levels of aromatic hydrocarbons in service stations. Ann Occup Hyg; 49(3):233-40.

Aleemuddin M; Babu MG; Manjunath ML; Quadri SS. (2015). Effects of chronic inhalation of petroleum products on haematological parameters. Int J Curr Res Acad Rev. 2015; 3(4):196-201

Gupta S and Dogra TD; (2002). Air pollution and human health hazard; Indian J. of Occup Envir Med. 6; 89- 93.

Azari MR; Konjin ZN; Zayeri F; Salehpour S; Seyedi MD. (2012). Occupational exposure of petroleum depot workers to BTEX compound. Int J Occup Environ Med; 3: 39-44.

American Conference of Government and Industrial Hygienist manual on environmental health. (1993); 1; 18- 24.

Azeez OM; Anigbogu CN; Akhigbe RE. (2015). Cardiotoxicity induced by inhalation of petroleum products. J. Afr. Ass. Physiol. Sci. 3 (1): 14-17.

Akintonwa, A. and Oladele. T.T. (2003). Health effect of exposure to hydrocarbon on petrol filling 
station attendants in Lagos. Nig. Ot. J. Hosp. Med 1 13(1-2)

Azeez OM and Akhigbe RE (2012a). Variability in cardiovascular functions and baroreflex sensitivity following inhalation of petroleum hydrocarbons. J. Cardiovasc Dis Res; 3: 99-103

Levecchio C. F. and Fulton SE. (2001). Ventricular fibrillation following inhalation of Glade Air Freshener. Eur J Emerg Med; 8:153-4.

Mills NL; Tornqvist H; Robinson SD; Gonzalez M; Darnley K; MacNee W; Boon NA; Donaldson K; Blomberg A; Sandstrom T; Newby DE. (2005). Diesel exhaust inhalation causes vascular dysfunction and impaired endogenous fibrinolysis; circulation.112 (25): 3930-6

Levy MN; Pappano AJ. (2007). Cardiovascular Physiology. 9th ed. Maryland Heights, Missouri: Mosby Elsevier. p. 379.

Bartoli CR; Wellenius GA, Diaz EA; Lawrence J; Coull BA; Akiyama I; Lee LM; Okabe K; Verrier RL; Godleski JJ (2009). Mechanisms of inhaled fine particulate air pollution-induced arterial blood pressure changes. Environ Health Perspect. 117 (3): 361-366
Sanong WF (1997). Review of Medical Physiology. 18th ed. San Fransisco: Lange Medical Publisher, MC Graw Hills;

Anderson CE and Loomis G. (2003). Recognition and prevention of inhalant abuse. Ann Fam. Physician.; 68:869-74.

El-Menyar AA; El-Tawil M; AI Suwaidi JA. (2005). eenager with angiographically normal epicardial coronary arteries and acute myocardial infarction after butane Inhalation. Eur J Emerg Med; $12: 137-41$

Ritchie GD; Bekkedal M; Bobb A; Arfsten D. (2003) Radiological and health effects of exposure to kerosene- based jet fuels and performance additives. J Toxicol. Envron. Health B Crit Rev; $6: 357-451$ 